Andrzej Lisowski

\title{
RESIDENTIAL PREFERENCES IN NIGERIA: A CASE STUDY OF ANAMBRA STATE
}

Man is a strategist who continually makes choices between the alternative ways of acting. The choices are determined by his knowledge and experiences, systems of values, emotional involvement, quantity and quality of the information obtained, affiliation to the particular social and cultural system, etc. One of the research trends in the behavioural geography is the study of attitudes and preferences which was undertaken in geography by Gould (1966). The trend is focused not so much on identification of spatial distribution of preferences as on searching the relationships between those preferences and attitudes on the one hand and properties of preferred places and individual features of the reviewed participants on the other.

Research on residential preferences in Nigeria was undertaken by Gould (1966) and Gould and Ola (1970) on a country and regional scale. The research has shown that in Nigeria, in spite of the existing decentralisation tendencies, local residential preferences are marked by a relatively high compatibility regardless of places of origin and tribal affiliation. Generally speaking, the degree of compatibility of preferenoes was higher than in the case of the reviewed students in the USA (in Nigeria $62.5 \%$, Pensylwania $46 \%$, Alabama $28 \%$ ). Usually, the economically better developed and urbanized regions were chosen (the south and middle-north). The analysis of the surface trend showed a decline of the attractiveness of the country from the south-west to the north-east.

This paper comprises the results of preliminary research on residential preferences in Nigeria on the example of the state of Anambra, conducted with the participation of undergraduates from the University of Nigeria at Nsukka. The purpose of the study was to identify residential preferences in relation to the settlements of various size as well as criteria which deterimine the residents' choices (what properties attract the population to the particular class of settlements) with reference to the features of the participants (sex, age, education level, income level and marital status).

The source of the information were the interviews conducted in four 
localities of the State of Anambra. Participants were the residents of the particular localities. Enugu is a city with 300 thousand inhabitants of supra-regional importance, with differentiated functions, one of the seven most important urban centres in Nigeria. Nsukka $(60 \mathrm{~km}$ from Enugu) is a local centre (around 70 thousand inhabitants) with a certain regional specialisation in the domain of educational functions (a university, 14 secondary schools). Although statistically it is a middle-sized town, it has many characteristics of a village, being marked by an attractive micro-climate and better water supply than in the neighbouring villages on the plateau. Ihakpu-Awka is a village situated $40 \mathrm{~km}$ north of Nsukka, and Nkpunato-Nkpologu $-40 \mathrm{~km}$ west of Nsukka. The number of the inhabitants of each of those villages does not exceed 5 thousand and there are no central functions in these settlements.

Altogether, a thousand questionnaires were prepared from which 790 were used for further analysis (Enugu 250, Nsukka 245, Ihakpu-Awka 150 and Nkpunato-Nkpologu 145). The study of residential preferences consisted of two parts: The first question concerned the most desirable place of residence: where would you like to reside? according to the following pattern: Lagos; Enugu or other city; Nsukka or other town; village. In the second part of the questionnaire the respondents were supposed to substantiate their preferences in light of the most positive properties attracting to the given locality. The method of the partially open questions was used, which described positive features of the particular settlements in the following classes: economic factors, technical and social facilities, social enviroment, physical enviroment, other. Some of the possible answers were relative, that is they indicated a lesser intensification of negative features in comparison with another class of settlements (for example, a lesser crime in villages than in a city).

Among 790 participants, $28.6 \%$ would like to live in Lagos, in Enugu $29.9 \%$, in Nsukka $25.2 \%$, while in villages only $16.3 \%$. Proportions of preferences regardless of the place of residence are similar. The largest dissimilarities in preferences are observed in relation to Lagos and Nsukka $(12-14 \%)$. The villagers mostly prefer a big and very big city $(63.8 \%)$, which are to a lesser extent preffered by the residents of Nsukka $(48.5 \%)$, while in Enugu $62 \%$. Lagos is the most desirable place of residence for the inhabitants of the villages $(34.6 \%)$ of whom only $14.6 \%$ would like to remain in the countryside. On the other hand, almost one third of the inhabitants of Enugu and Nsukka would like to stay where they are living now. The next place is occupied by the settlement which is hierarchically higher, that is Lagos for the residents of Enugu and Enugu for the inhabitants of Nsukka. Irrespective of a clear-cut preference for utban areas $(83.7 \%)$, no attachment of the urban population to their present places of residence can be observed, which is normal in a society on the initial stage of an intensive urbanisation. Preferences of the residents 
of Enugu and Nsukka partly confirm the step-wise migration pattern, according to the hierarchy of settlement (Conway 1980), and high evalution of Lagos among poor villagers confirm the phenomenon, which is frequent i.a. in West Africa, of a direct migration to the largest cities, which consitute a stereotype of a "better life" and a chance of raising social status ${ }^{1}$.

In case of Lagos the participants regarded as the most positive such features of the metropolis as the quality and access to social facilities $(46.9 \%)$, as well as economic factors, including job opportunities, and higher income $(31.4 \%)$. In Enugu the two classes of attributes of the environment of a big city are equally important $(39.4 \%$ and $38.6 \%$ respectively). The villagers regard the acces to social and technical facilities as more important, whereas economic factors are more important for residents of urban centres. Similar results were obtained in research carried out simultaneously in Lagos, where the residents of the capital city are less inclined to mention social facilities among advantages of a big city, being probably more aware of shortcomings in this field. Quality of social environment of a big city, bound up with a higher heterogeneity and smaller control from the traditional community, are perceived to a lesser extent by the town dwellers (as in the case of social facilities), but they play a major part among villagers.

Advantages of a smaller town differ most in consciousness of the inhabitants. A smaller town is attractive i.a. due to its relatively higher employment opportunities than in a village and a lower cost of living than in a big city. $(44.2 \%)$; on the other hand, quality of the physical environment, such as lesser noise, pollution and density than in. a city $(22.1 \%$, and of the social environment, due to lower crime than in a city $(17.1 \%)$ are percevied. Social facilities are evaluated low $(10 \%)$, its importance being emphasized by the residents of Nsukka. Quality of the physical environment of Nsukka are mainly perceived by the inhabitants of the city of Enugu (31.7\%).

Advantages of the physical environment of a smaller town are emphasised to a higher extent than those of the village (!) In case of villages the most highly perceived feature is the social environment $(59.7 \%)$. What is

1 The investigation conducted in the zone of Lafia Agricultural Development Project (World Bank) in the State of Plateau (Nwoko, Mabawonku 1983) indicated that 58\% of peasants would like their children to work in town (chiefly due to poverty and absence of social facilities), and $42 \%$ would prefer their children to stay in the country and work as peasants. In Anambra, however, the level of urbanisation and non-agricultural employment are higher among the population (according to the National Atlas of Nigeria above $50 \%$ in 1963 , while in Benue Plateau below $30 \%$. The Ibo are also characterised by a higher level of education and comparatively high spatial mobility. For example, in 1976 in Lagos, less than $0.1 \%$ of total population came from the state of Plateau, whereas $1.8 \%$ came from Anambra and $4.2 \%$ from Imo. 
mainly emphasised is the lower crime; another attracting factor is the acquaintance with people and traditional mutual assistance in difficult situations. Advantages of the social environment are particularly emphasised by the inhabitants of Enugu $(75 \%)$, whereas the inhabitants of Nsukka and villagers also perceive quality of the physical environment $(14.7 \%)$ as well as lower cost of living than is the case of a town $(14.7 \%)$.

Participants who prefer to reside in Lagos are chiefly people at the age of $15-39$ years $(64.9 \%)$ with more than primary education $(69.2 \%)$ with average $(31 \%)$ and high $(41.6 \%)$ income. People at the age of 15-39 $(65.2 \%)$, with supra-primary education $(61 \%)$ and higher income $(55.3 \%)$ and having more than primary education $(63.3 \%)$ would prefer to live in a small town. Elderly people, above 50 years of age $(44 \%)$ with low income $(69 \%)$ and no more than primary education $(82.9 \%)$ would like to live in villages. Sex and marital status did not exert a visible impact on preferences.

At the time of rapid urbanisation and industrialisation people prefer to live in urban areas $(83.7 \%$ ) due to the existent high disprortion in the living standard between rural and urban areas (according to the ILO report in 1978 1:4.5). According to Makinwa (1978), young emigrants from villages to Benin City in $45.6 \%$ explained their migration as the willing to acquire education or raise their qualifications and in $28.2 \%$ as the opportunity of getting a job. Big cities enjoy people's highest interest, since they play to a high extent in people's consciousness the role of a stereotype area of a better life and advancement in social hierarchy. they were prefered by $47 \%$ of participants with low income. Those cities were chosen by $69.1 \%$ participants at the age of $15-39$ years, $65.2 \%$ of participants with more than primary education and $72.7 \%$ of people with higher income. A town does not enjoy such an interest from the younger people and people with higher income.

Results confirm that the inhabitants are aware of negative aspects of the environment of big cities (crime being the leading one) but they are unable to veil the advantages of general living standards. The results of determinants of spatial choices obtained here do not differ much from studies on the perception of other urban areas for example in Kenya (Barker and Ferguson 1983). The regional capital of Enugu seems to be competitive in relation to the Lagos metropolis. This tendency was also observed in other developing countries, for example in Tanzania (Gould 1969), Papua New Guinea (Weinand, Ward 1979), and Venezuela (Jones 1978), in which some authors see the influence of a negative picture of capital cities in mass media of those countries (Jones 1978). 


\section{REFERENCES}

B arker, D., Fergus o n, A. G., 1983, "A goldmine in the sky faraway rural-urban images in Kenya", Area 15, pp. 185-191.

C o n way, D., 1980, "Step-wise migration: toward a classification of the mechanism", International Migration Research 14, pp. 3-14.

G o u l d, P. R., 1966, "On mental maps". Michigan Inter University Community of Mathematical Geographers. Discussion Paper 9. Reprinted in: Downs R. M., Stea, D., (1973), Image and Environment. Aldine Press: Chicago, pp. 182-220.

G o u l d, P. R., 1969, "The structure of space preferences in Tanzania", Area 1, pp. 29-35.

Gould, P. R., Ola, D., 1970, The perception of residential desirability in the Western region of Nigeria", Environment and Planning B, 2, pp. 73-87.

J on es, R: C., 1978, "Myth maps and migration in Venezuela", Economic Geography 54, pp. 75-91.

M a k i n w a, P. K., 1978 "Determinants and Impact of Rural-Urban Migration in Bendel State: A Case Study of Six Villages", Research Report No.2, Centre for Social Cultural and Economic Studies, University of Benin, Benin City.

N wok o, A. F., M a b a w on k u. A. F., 1983, "Welfare Indicators for Farmers in Lafia Agricultural Development Project Area", in: Ibozurike, W. M., Raza, R. (eds) Rural Nigeria: Development and Quality of Life. AR MTI Ilorin, pp. 252-260.

We in a nd, H. C., Wa r d, R. G., 1979, "Area preferences in Papua New Guinea", Australian Geographical Studies 17, pp. 64-75. 
